\title{
Interregional Occupational Structures And Race Vis-A-Vis The Income Distribution
}

\author{
G. RANDOLPH RicE*
}

\section{INTRODUCTION}

The economic literature of the past ten years or so has devoted substantial attention to the many facets of personal income distribution. The chief direction of these studies has been noted by Jacob Mincer in his survey article on the distribution of labor incomes: "While traditional and mainly speculative preoccupations with factor shares, ability vectors, and stochastic processes continued in evidence, the dominant form of research was empirical . . . (more specifically) beyond the usual and necessary efforts to summarize, measure, and occasionally interpret the be-wildering varieties of statistical frequency distributions of income, some of the new studies attempt multivariate statistical analysis of 'causal' factors associated with size of individual income." One impressive, and perhaps the dominant, strain in these model developments has been the human capital theories which come directly from economic theory and thus, theoretically, provide an explanation for the different shapes among income distributions." Therefore, to the extent possible, the level of human capital, whether implicitly or explicitly specified, should be recognized in any model of income distribution. ${ }^{3}$ Human capital decisions of individuals can take many forms, such as educational expenditures and relocation decisions; however, as noted by Lester Thurow ... "choosing an occupation is probably the major human capital decision [along with all of the subsidiary decisions that occur within that decision]". ${ }^{4}$ Yet the stratification of individuals among and within occupations has received minor notice in the previous "causal" models of income distributions. ${ }^{5}$ More precisely, to my knowledge, no study has focused singularly on the role of the occupational mix for purposes of predicting areal income distribution. ${ }^{6}$ Hence, one objective of this study is to predict the shape of interstate income distributions-specifically, the income distribution of families-via occupational mix, and thereby give explicit notice to this human capital dimension.

A second objective of this study is to use the occupational model to offer some empirical evidence on interregional racial differences vis-a-vis the income distribution. Gary Becker has defined a coefficient of discrimination to measure a "taste for discrimination" in money terms for different factors of production and employers, where it is assumed that the factors of production are equally productive. ${ }^{7}$ Using these aspects of the Becker framework and a white/nonwhite delineation of the occupational strata, the model looks at the extent to which regional differences in "taste for discrimination" in money terms have existed.

*Associate Professor of Economics, Louisiana State University, Baton Rouge, Louisiana. 
More specifically, the cases of interregional white/nonwhite income differentials which are attributable to differences in economic capacity, e.g., regional differences in quantity of education and scholastic achievement, are well documented and need not be repeated here. ${ }^{8}$ However, the unexplained portion of the interregional disparities in racial income differentials-i.e., after correction for capabilities-, or employment discrimination, has received little empirical attention in being decomposed into its two "taste for discrimination" effects: first, interregional differences in the extent to which qualified nonwhites are excluded from certain occupations, and second, interregional differences in the extent to which whites experience income gains by appropriating part of the nonwhite wages per occupation. $^{9}$ The proposed income distribution model of this study lends itself to viewing the latter.

\section{THE MODEL}

The economic climate of an area is very much dependent upon the occupational strata of that region. One consideration making the relative occupational distribution a measure of performance readily studied is that it can be made independent of interindustry wage patterns. ${ }^{10}$ For when the ... "distribution of wages and salaries is disaggregated by industrial origin, the component distributions of earnings must, to some extent, reflect differences in the occupational compositions of the various industries. Such differences exist, no matter what boundaries are imposed on the concept of industry . . . From the point of view of organization of the production process, an industry is a particular combination of factors of production. When labor is subdivided by occupations differing in training and skill, it can be viewed as a set of distinct factors of production differing in the extent of capital accumulated in them." ${ }^{11}$

Thus, in practice, different occupations require varying degrees of education and training. However, these seemingly rigid requirements for entry into some occupations, the lack of any formal training for others, and the continuum of "investments" for the intermediate occupations are not intended to imply homogeneous groupings at each level. In fact, within occupations there is a wide dispersion of earnings, due in part to ability, but additionally affected by personality traits, health, luck, and so forth. ${ }^{12}$ Also, other considerations interact to influence both the interoccupational differences, principally a result of "capital ratios", and the intraoccupational differences; examples include social and cultural patterns and deliberate collective decisions by governments and unions. Hence, the aggregate shape of an areal income distribution can for the most part be attributed to skewness among and within occupational categories. Conceptually, the current model presumes that at an observable point in time the supply and demand conditions for the occupational format are realized, i.e., the distribution among occupations is in equilibrium; consequently, given this dispersion, the income distribution becomes a function of the dispersion within occupations as delineated by income size classes.

The role of racial differences in the occupational structure has proven to be the most problematic of the extramural factors of occupational stratification. ${ }^{13}$ 
Simple descriptive statistics have shown that nonwhites tend to cluster at the lower end of the income distribution, even within occupational classifications. As noted above, this differential phenomenon has been viewed from two perspectives: (a) a differential resulting from differences in productivity factors not directly related to employment discrimination, and (b) a residual unaccounted for in the differences in productivity factors and which may result largely from employment discrimination. In the Becker discrimination model, the employment discrimination case applies to factors of production (workers) which are equally productive, but who find that the employers face a net wage rate of $\mathrm{W}\left(1+\mathrm{d}_{\mathrm{i}}\right)$ for them, where $d_{i}$ is the discrimination coefficient against this factor. That is, the employer is willing to pay the favored workers $\left(\mathrm{W}+\mathrm{d}_{\mathrm{i}}\right)$ and the ones discriminated against $\left(\mathrm{W}-\mathrm{d}_{\mathrm{i}}\right)$, so that $\mathrm{W}_{\mathrm{W}}$ is the wage of white workers and $\mathrm{N}_{\mathrm{NW}}$ is the wage of nonwhite workers and with discrimination $\mathrm{W}_{\mathrm{W}}>\mathrm{W}_{\mathrm{NW}} \cdot{ }^{14}$

The fact that occupations require their specific "capital ratios" provides a good approximation of equally productive factor inputs across regions. Thus, by delineating regional occupational strata into white and nonwhite factions, it is possible to deduce via the occupational predictive model the nature of differences in the taste for employment discrimination among the regions. Hence, the question here is not whether regional differences in overall racial discrimination, past or present, do exist (the earlier studies alluded to above have provided positive conclusions on this point),,$^{15}$ but rather whether regional differences in tastes for employment discrimination ${ }^{16}$ are embodied in (a) nonwhites being denied entry to certain occupations, or (b) whites creating income gains by appropriating part of the nonwhite wages per occupation. We shall test for the latter; then, if regional differences do not exist, we can accede to the former.

The particular form of the model follows a recursive bent. First, it is assumed that there is an existing interoccupational structure to the extent that the number of whites and nonwhites within each occupation is exogeneously specified and equal to the actual number of individuals "residing" in each. Since distinct occupations embody derived "capital ratios" of similar content, this assumption presumes realized supply and demand conditions for overall human capital traits. Consequently, differential racial proportions per occupation result from either divergent economic capabilities per race or effective exclusion of capable individuals from certain occupations based on race. The case of interregional differences in racial economic capabilities was noted above ${ }^{17}$ the case of exclusion will be implicitly extracted later, but for the time being we simply take as given the number of whites and nonwhites in the respective occupations in each region.

Continuing in the first phase of the model, it is assumed that there exists a hypothetical "expected" structure of earnings, aggregated by income size classes, within occupations (constant capital groups), and that this remains consistent for whites and nonwhites across regions. Specifically, this assumption states that the proportion of individuals in the $\mathrm{i}^{\text {th }}$ income class per occupational classification is invariant across regions. Conceptually, there are some a priori reasons 
for believing this phenomenon to be true as a first approximation, ${ }^{18}$ but at this stage of the model, the importance of the assumption is to offer a standard for comparing the actual interregional differences in the occupational/income structure. The standards are the expected number of whites $\mathrm{E}\left[\mathrm{NO}{ }_{(\mathrm{w})}\right]$ and nonwhites $\mathrm{E}\left[\mathrm{NO}{ }_{(\mathrm{nw})}\right]$ in the $\mathrm{j}^{\text {th }}$ occupation in the $\mathrm{i}^{\text {th }}$ income class for the $\mathrm{k}^{\text {th }}$ region, which mathematically are:

$$
\begin{aligned}
& \mathrm{E}\left[\mathrm{NO}_{(\mathrm{w}) \mathrm{ij}}\right]_{\mathrm{k}}=\mathrm{W}_{\mathrm{jk}} \quad \mathrm{x} \mathrm{b}_{\mathrm{ij}} \\
& \mathrm{E}\left[\mathrm{NO}_{(\mathrm{nw}) \mathrm{ij}}\right] \mathrm{k}=\mathrm{NW}_{\mathrm{jk}} \times \mathrm{b}_{\mathrm{ij}}
\end{aligned}
$$

where $\mathrm{W}_{\mathrm{jk}}$ = number of whites in the $\mathrm{j}^{\text {th }}$ occupation in the $\mathrm{k}^{\text {th }}$ area

NW ${ }_{j k}=$ number of nonwhites in the $\mathrm{j}^{\text {th }}$ occupation in the $\mathrm{k}^{\text {th }}$ area and

$\mathrm{b}_{\mathrm{ij}}=$ proportion of jobs in the $\mathrm{j}^{\text {th }}$ occupation in the $\mathrm{i}^{\text {th }}$ income class for the U.S., i.e., without regard to race.

The interpretation of this expected value is that given the interoccupational structure, the intraoccupational population distribution among income size classes would be proportionally equivalent across regions regardless of race. The fact that these values may be more removed from the actual nonwhite distribution than for the white distribution, or vice versa, is inconsequential in questioning interregional differences in tastes for discrimination; rather, the issue involves interregional uniformity between actual and expected values within each race. This uniformity is also important in the overall hypothesis of general occupational strata as an important predictive agent of the shape of areal income distributions.

When the "expected" employment for each occupation in the respective income size is computed, by race, the value is compared in the second stage with actual employment. The results are used to predict the proportion of whites and nonwhites in the $\mathrm{i}^{\text {th }}$ income size class in the $\mathrm{k}^{\text {th }}$ area as follows:

$$
\begin{aligned}
& \mathrm{Y}_{\mathrm{ik}}=\sum_{\mathrm{j} \text { (w) }}\left[\begin{array}{l}
\begin{array}{l}
\text { Actual number of whites in } \\
\text { the } \mathrm{j}^{\text {th }} \text { occupation in } \\
\text { the } \mathrm{i}_{\text {th }} \text { income size class } \\
\mathrm{E}\left[\mathrm{NO} \mathrm{O}_{(\mathrm{w}) \mathrm{ij}}\right]_{\mathrm{k}}
\end{array} \quad \mathrm{x} \quad \beta_{\mathrm{ij}_{(\mathrm{w})}}
\end{array}\right]+\mathrm{e}_{\mathrm{ik}}(\mathrm{w}) \\
& =\sum_{j}\left[\frac{A_{i j_{(w)}}}{E\left[N O_{(w) i j}\right]_{k}} \quad x \quad B_{i j_{(w)}}+e_{i k}(w)\right]
\end{aligned}
$$

where $\mathrm{Y}_{\mathrm{ik}}$ is is the proportion of white incomes in the $\mathrm{i}^{\text {th }}$ income size class in the $\mathrm{k}^{\text {th }}$ area; $B_{\mathrm{ij}}$ is) is a parameter to be estimated representing an assumption of "expected" constancy among regions, the merit of which is left to empiricism; and $\mathrm{e}_{\mathrm{ik}}$ is) is the random disturbance term for this stochastic equation. Similar- 
ly, for nonwhites:

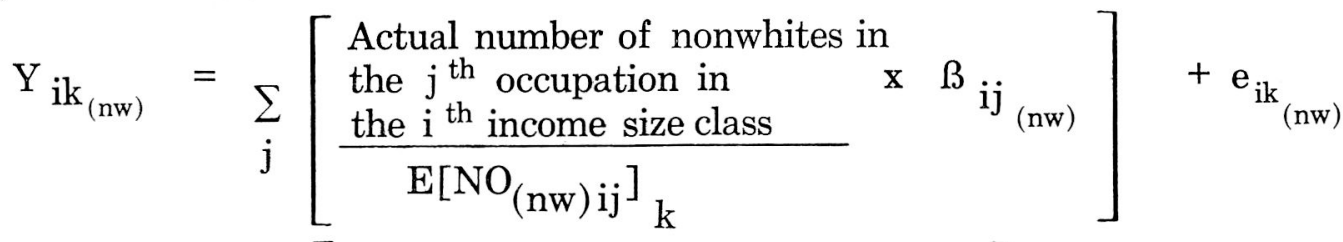

$$
\begin{aligned}
& =\sum_{j}\left[\frac{A_{i j_{(n w)}}}{E\left[N O_{(n w) i j}\right]_{k}} \quad x \quad B_{i j_{(n w)}}\right]+\mathbf{e}_{i k_{(n w)}}
\end{aligned}
$$

where the notation is only altered by the nonwhite (nw) subscript. The interpretation of $\frac{A_{i j}}{E[\mathrm{NO}] \mathrm{k}}$ whether for whites or nonwhites, points to the fact that in a specific income size class the actual number of jobs exceeds, equals, or falls short of the expected employment of a homogeneous (constant capital) occupational income size class population. The first objective of the model is to predict the areal income distribution via the occupational structure, the ultimate verdict of the approach being an empirical question. The second objective is to see if the interregional explanatory abilities differ for the white versus nonwhite delineations. Since occupational groupings are assumed to embody constant capital requirements, different predictive abilities per race across income classes would indicate interregional differences (different degrees of regional variability in $\frac{A_{i j}}{E[N O] k}$ per income class) in tastes for discrimination, i.e., $\left(W \pm d_{i}\right)$; if predictive ability per race across income classes is not notably different, we could conclude that interregional income differentials between whites and nonwhites which is unaccounted for by differences in productivity factors is chiefly a result of variable regional tendencies to deny nonwhites proportionate entry to certain occupations.

\section{EMPIRICAL RESULTS}

Much concern in personal income distribution theory and practice has centered around the distribution of income between families, and consequently, this focal unit is the specific size distribution of income to be predicted from the occupational model. The observational units are states, disaggregated along racial lines. However, since nonwhites do not represent a significant proportion of the total labor force in some states (in some cases, separate data are not available by race), the sample is limited to those states in which the nonwhite population represents five percent or more of the total population. ${ }^{19}$ Data are from the 1960 Census of Population. The proportion of incomes which fall into the following ten size classes are the variables to be estimated for the whites and nonwhites:

$$
\begin{aligned}
& \text { Under } \$ 1,000 \\
& \$ 1,000-1,999 \\
& \$ 2,000-2,999 \\
& \$ 3,000-3,999 \\
& \$ 4,000-4,999
\end{aligned}
$$




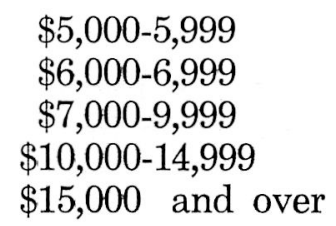

For predicting family income distributions, the independent variables are the proportions of employment for families with heads in the civilian labor force for the following eleven occupational categories, by color: ${ }^{20}$ Professional, Technical, and Kindred Workers; Farmers and Farm Managers; Managers, Offs., and Propr's, excluding Farm; Clerical and Kindred Workers; Sales Workers; Craftsmen, Foremen, and Kindred Workers; Operatives and Kindred Workers; Private Household Workers; Service Workers, excluding Private Household; Farm Laborers, excluding Unpaid and Foremen; and Laborers, excluding Farm and Mine. The regression results, by race, are sum narized in Table $1 .^{21}$

TABLE 1

$\mathrm{R}^{2}$-Whites and Nonwhites

\begin{tabular}{llc}
\hline Income Class & $\begin{array}{c}\text { Whites } \\
\mathrm{R}^{2}\end{array}$ & $\begin{array}{c}\text { Nonwhites } \\
\mathrm{R}^{2}\end{array}$ \\
\hline Under $\$ 1,000$ & $0.86^{*}$ & $0.90^{*}$ \\
$\$ 1,000-1,999$ & $0.96^{*}$ & $0.97^{*}$ \\
$\$ 2,000-2,999$ & $0.99^{*}$ & $0.95^{*}$ \\
$\$ 3,000-3,999$ & $0.98^{*}$ & $0.89^{*}$ \\
$\$ 4,000-4,999$ & $0.87^{*}$ & $0.97^{*}$ \\
$\$ 5,000-5,999$ & $0.81^{*}$ & $0.99^{*}$ \\
$\$ 6,000-6,999$ & $0.94^{*}$ & $0.99^{*}$ \\
$\$ 7,000-9,999$ & $0.97^{*}$ & $0.99^{*}$ \\
$\$ 10,000-14,999$ & $0.99^{*}$ & $0.99^{*}$ \\
$\$ 15,000$ and over & $0.97^{*}$ & $0.98^{*}$ \\
\hline
\end{tabular}

*Significant at the 1 per cent level

Of the $20 \mathrm{~F}$-statistics, all 20 are significant at the one percent level. The lowest $R^{2}$ (uncorrected) is 0.81 . On the whole, the model predicts uniformly well for whites and nonwhites, and thus tends to dispel the prospect of interregional differences in discrimination in the form of whites appropriating part of the nonwhite wages for similar capital-constant groups. The least satisfactorily predicted class for both groups is the "under $\$ 1,000 "$ " This result is most likely linked to the types of income accruing to families at this level. In particular, for this size class transfer payments play a significant role toward the aggregate income received and, thus, serves as a plausible explanation for the relative ineffectiveness of the predictive model.

The fact that the occupational model predicts the shape of interstate income distributions very well leaves little doubt that occupational strata is an extremely important variable for studying income inequality. Furthermore, the racial de- 
lineation offers evidence that interregional differences in the extent of nonwhite/ white income differentials which is unaccounted for by differences in productivity factors has been due in large part to variable regional tendencies to deny nonwhites proportionate entry to certain occupations. ${ }^{22}$

\section{CONCLUSION}

Among those factors which have proven important in the trend toward greater income inequality in recent years is the occupational upgrading of the employed labor force. ${ }^{23}$ This general observation lends credence to the above hypothesis and the chosen methodology in predicting personal income distribution. To the extent occupational movements prove responsive to labor demands, then the altering renumerations become important to the distribution of personal income, as witnessed by the predictive ability of the model. The racial delineation indicates that regional differences in "employment discrimination" (a component of interregional income differentials) are chiefly manifested by diverse racial occupational distributions beyond that justified by a difference in qualifications rather than the case of some regions being more pronounced than others in paying nonwhites less than their white occupational counterparts.

\section{DATA SOURCE:}

Income and Occupational Data: Bureau of the Census, U.S. Census of Population, 1960.

\section{FOOTNOTES}

1Jacob Mincer, "The Distribution of Labor Incomes: A Survey," Journal of Economic Literature, vol. 8 (March 1970), p. 1.

2 Noteworthy contributors to the theory of human capital include: Gary S. Becker, Human Capital (New York: Columbia University Press, 1964) and Human Capital and the Personal Distribution of Income: An Analytical Approach (Ann Arbor: University of Michigan, 1967); Barry R. Chiswick, "Human Capital and the Distribution of Personal Income", unpublished Ph.D. dissertation, Columbia University, 1967; Becker and Chriswick, "Education and the Distribution of Earnings", The American Economic Review, vol. 56 (May 1966), pp. 358-369; Jacob Mincer, "Investment in Human Capital and Personal Income Distribution," The Journal of Political Economy, vol. 66 (August 1958), pp. 281-302; and T. W. Schultz, "Investment in Human Capital", The American Economic Review, vol. 51 (March 1961), pp. 1-17.

${ }^{3}$ An additional, contrasting (yet equally important) example of the "causal" approach is found in studies which use a wide variety of social, economic, and demographic factors to explain via statistical models interarea variations in income inequality. Example include: Ahmad Al-Sammarie and H. P. Miller, "State Differentials in Income Concentration," The American Economic Review, vol. 57 (March 1967), pp. 59-67, and Tom S. Sale, III, "Interstate Analysis of the Size Distribution of Family Income, 1950-1970", Southern Economic Journal, vol. 40 (January 1974), pp. 434-441.

${ }_{4}^{4}$ Lester Thurow, Investment in Human Capital (Belmont, Calif.: Wadsworth Publishing Company, Inc., 1970), p. 28.

5 For example, Sale, op. cit., p. 438, hypothesizes that . . "the occupational structure of an area is also [i.e., among several possible variables] expected to have an impact on income inequality of the region. Specifically, the larger the proportion of workers that are craftsmen, clerical, or operative workers, then the lower the expected inequality measure". This variable recognizes that traditionally these occupations are characterized by the lowest intraoccupational income inequality, and hence a strong a priori basis for inclusion in the explanatory structure. But in the Sale model, the empirical results are disappointing to the point of saying little about occupational effects.

6Joseph P. Newhouse, "A Simple Hypothesis of Income Distribution" Journal of Human Resources, vol. 6 (Winter 1971), pp. 51-74, has taken a different tack by focusing on the industry mix of an area for explaining the areal income distribution.

${ }^{7}$ Gary S. Becker, The Economics of Discrimination (Chicago: The University of Chicago Press, 1971). 
8For example, see James Gwartney, "Discrimination and Income Differentials," The American Economic Review, vol. 60 (June 1970), pp. 396-408.

${ }^{9}$ Robert E. Hall and Richard A. Kasten, "The Relative Occupational Success of Blacks and Whites", Brookings Papers on Economic Activity (3: 1973), pp. 781-795, have studied the occupational and wage dimensions of blacks relative to whites for the U.S., but do not get into interregional differences in the "taste for discrimination".

${ }^{10}$ Barbara R. Bergman and Jerolyn R. Lyle, "The Occupatioal Standing of Negroes by Area and Industries," The Journal of Human Resources, vol. 6 (Fall 1971), pp. 411-433.

11Mincer, "Investment in Human Capital and Personal Income Distribution," p. 299.

12Harold Lydall, The Structure of Earnings (Oxford: The Clarendon Press, 1968), p. 105.

${ }_{13}$ Noteworthy studies of the occupational/race issue include: Becker, The Economics of Discrimination; Richard B. Freeman, "Changes in the Labor Market for Black Americans, 1948-1972," Brookings Papers on Economic Activity (1: 1973), pp. 67-120; James D. Gwartney and Kenneth M. McCaffree, "Variance in Discrimination Among Occupations", The Southern Economic Journal, vol. 38 (October 1971), pp. 141-155; and Hall and Kasten, "The Relative Occupational Success of Blacks and Whites".

${ }_{14}$ For a synopsis of the Becker theory in particular and racial discrimination in general, see Ray Marshall, "The Ecoonmics of Racial Discrimination: A Survey", Journal of Economic Literature, vol. 12 (September 1974), pp. 849-871.

15For example, Gwartney, "Discrimination and Income Differentials", p. 407, has concluded that . . . "even after correction for age, education, and scholastic achievement differences, the adjusted nonwhite/ white earnings ratio is greater in the North than the South". That is, regional differences above and beyond the past discriminatory influences.

16Recall that employment discrimination is distinguished by income differentials not accounted for by differences in productivity factors. The issue here is not whether regional differences in employment discrimination exist-for according to such studies as Gwartney, "Discrimination and Income Differentials", they do -, but rather to question the nature of interregional tastes for employment discrimination.

17 Ibid.

18 For example, we might reason that overall labor market structures tend to be national in scope e.g., the higher skilled occupations have shown a propensity to migrate when economic disequilibria exist between regions. Newhouse, op. cit., hypothesized in his industry mix model that an industry's wage structure is invariant across geographical areas based on the following reasons: (1) the probable similarity of technology within an industry among regions; (2) the trading by industries in national markets and thus the tendency for equalization of marginal revenue products; and (3) national unionization eliminating geographical differentials.

19The included states are: Alabama, Arizona, Arkansas, California, Delaware, Florida, Georgia, Illinois, Indiana, Kentucky, Louisiana, Maryland, Michigan, Mississippi, Missouri, New Jersey, New Mexico, New York, North Carolina, Ohio, Oklahoma, Pennylvania, South Carolina, Tennessee, Texas, and Virginia. Although Nevada showed a nonwhite population representing $7.7 \%$ of the total and, as such, should be included in the study, the absolute numbers were so small that they were not tabulated for nonwhites separately. For this reason, Nevada is excluded.

20 As noted above, it is recognized that factors other than racial differences (and discrimination) could be at work in influencing the income differences between white families and nonwhite families. In particular, differential savings and investment patterns, different endowments of inherited wealth, differential propensities for employment by other family members, and so forth are possible influences. However, the hypothesis specifically considers white and nonwhite family heads in identical occupations, i.e., homogeneous human and nonhuman capital groups, and, thus, attempts to capture the predominant income factor for the family.

21The regressions will be made available upon request by interested readers.

22 This conclusion is generally corroborated from a different methodological bent in Bergman and Lyle, op. cit., p. 412: "The basic act which characterizes the difference in the treatment of equally qualified whites and Negroes in the labor market is the refusal of many employers to consider hiring Negroes (broadly, speaking, regardless of the pay at which they would be willing to work) when recruiting for all but a relatively narrow range of jobs. Employers' general willingness to hire Negroes for jobs considered to be of low status is coupled with a general unwillingness to hire them for jobs bearing higher status."

${ }^{23}$ Andrew F. Brimmer, "Inflation and Income Distribution in the United States," The Review of Economics and Statistics, vol. 53 (February 1971), p. 43. 